\title{
Driverless robocabs - challenges and solutions regarding chassis technology
}

Dr. Andree Hohm, N. Balbierer, S. Pla, R. Syrnik, Continental Teves AG \& Co. oHG

This manuscript is not available according to publishing restriction. Thank you for your understanding. 